\begin{tabular}{l} 
REsumo \\
Em sua origem, a clinica psica- \\
nalitica de crianças nos brindou \\
com os importantes aportes de \\
Melanie Klein e Anna Freud, \\
que nos apontaram a \\
especificidade dessa clinica. Se \\
o que antes ocupava as analis- \\
tas repercutia na técnica a ser \\
utilizada com crianças, nossa \\
proposição sustenta uma \\
especificidade ainda mais singu- \\
lar quando se trata de bebês, \\
uma vez que não se pode escutá- \\
los da mesma maneira que se \\
escuta uma criança que já ence- \\
na em seu brincar a apropria- \\
ção dos significantes do Outro. \\
Na atualidade, após décadas de \\
bistória clinica veremos que, \\
além da importância de uma \\
estratégia clinica apropriada ao \\
psiquismo infantil, será na re- \\
lação do inconsciente com a lin- \\
guagem que esta clínica encon- \\
trará subsídios que autorizem \\
uma intervenção analitica. \\
Descritores: bebês; clinica \\
psicanalitica; \\
psiquismo infantil. \\
\hline
\end{tabular}

\section{A CLÍNICA PSICANALÍTICA: DE CRIANÇAS A BEBÊS, UMA ESPECIFICIDADE}

A psicanálise de crianças, inaugurada pelo famoso pequeno Hans, foi empreendida numa situação ímpar, já que Freud o viu uma única vez e o tratamento, sob sua supervisão, esteve a cargo do pai, Max Graf ${ }^{1}$. Sem pretender fazer desta o protótipo da análise de crianças e sem que se fizesse uso da transferência como instrumento técnico, Freud, neste momento, conclui: "Só porque a autoridade de um pai e a de um médico se unia numa só pessoa, e porque nela se combinava o carinho afetivo com o interesse científico, é que se pôde, nesse único exemplo, aplicar o método em uma utilização para a qual ele próprio não se teria prestado, fossem as coisas

Psicanalista. Mestrado em Psicanálise pela Universidad de León - (León, Espanha), Especialização em Intervenção Precoce pela Escola Bahiana de Medicina e Saúde Pública, membrofundador do Núcleo Interdisciplinar de Intervenção Precoce da Bahia (NIIP) e membro do Espaço Moebius de Psicanálise, Salvador, BA, Brasil. 
diferentes" (Freud, 1909/1988a, p.15). Contudo, Freud (1933/ 1988b) abordaria de maneira mais incisiva a eficácia do tratamento analítico com crianças, embora a alusiva especificidade do psiquismo infantil culminasse numa modificação da técnica utilizada com os adultos. A consequente leitura do legado freudiano acerca da técnica e da estruturação do psiquismo infantil ficaria a cargo daqueles que se ocupariam do sofrimento psíquico na infância.

Se, por um lado, Anna Freud se incumbiu de ler ao pé da letra o enunciado freudiano, por outro, Melanie Klein (1975), apoiada na concepção de um Édipo mais precoce, defende a transferência desde o início e preconiza o brincar, uma atividade simbólica, como um substituto da associação livre. $\mathrm{Na}$ atualidade, passadas algumas décadas de história clínica, quando contamos com a fina leitura feita por Lacan da genialidade dos textos freudianos, os importantes trabalhos de Dolto, Winnicott, renomados psicanalistas contemporâneos, e inúmeras pesquisas que atestam as competências do bebê, somos convocados a pensar numa especificidade ainda mais peculiar para esta clínica, a qual traz em sua essência uma vocação para suscitar questões.

As perguntas que os psicanalistas se empenharam em responder acerca da especificidade daquela clínica ao longo dos anos parecem dar lugar ao espanto com que nos deparamos hoje ao mencionarmos a clínica psicanalítica de bebês. Esse espanto, solidário às questões que formulamos tentando dar conta dessa clínica parece incidir num ponto: se os bebês não falam, o quê e como escutá-los? E se os bebês não entendem, para quê e por que enchê-los de palavras que beiram a insensatez e esperar que sustentem esse delírio, mesmo se estas lhes pareçam música aos ouvidos? Dito de outro modo, qual a particularidade desta clínica? Que pressupostos teóricos a sustentam e autorizam uma intervenção por parte do analista?

As questões que se nos apresentam acerca da especificidade desta clínica que se delineia como da intervenção precoce requerem desdobramentos que operam desde a importância do primeiro tempo na constituição do psiquismo à asserção de que as estruturas clínicas, embora nela se originem, não se decidem na infância, e são não-decididas até que advenha a adolescência ${ }^{2}$. Alia-se a esta proposição a expressiva contribuição das neurociências, a qual veio corroborar alguns pressupostos psicanalíticos. Assim, temos, por um lado, um bebê prematuro do ponto de vista neuropsíquico exi- 
bindo competências e uma temporária e providencial plasticidade neuronal, sabidamente permeável ao significante do desejo do outro ${ }^{3}$. Jerusalinsky (2010) postula que esse tempo do bebê é caracterizado, principalmente, para além da plasticidade do sistema neurogenético, pela plasticidade das representações linguísticas que o caracteriza.

A prematuridade neuropsíquica do bebê, condição em que o tempo cronológico é vital para que certas funções orgânicas e psíquicas se valham da permeabilidade à incidência da linguagem evidencia, pois, o lugar decisivo do outro em um tempo preciso da constituição psíquica, à qual se atrela o desenvolvimento ${ }^{4}$. Nesse primeiro tempo, cabe à mãe ou cuidador instituir o campo do Outro, condição para o advento do sujeito. A submissão do filhote do homem à ordem simbólica imposta pela linguagem constitui, assim, uma condição prévia e absoluta da subjetividade e das relações que o sujeito estabelece com o outro. Por outro lado, o lugar do analista que, especialmente nesta clínica, é convocado a ocupar, na transferência, o lugar do Outro do bebê, dar sua contribuição libidinal enquanto semblante do objeto a visando promover mudanças na subjetividade dos pais até que se lhes restitua o lugar de legítimos outros do bebê.

Veremos que, apesar da importância atribuída às estratégias clínicas moldáveis à especificidade do psiquismo infantil, será na relação do incons- 
ciente com a estrutura da linguagem, resgatada por Lacan do texto freudiano, que dimensionaremos o lugar da escuta e da intervenção analítica. Segundo Vorcaro (2004, p.136) "A operação clínica que supomos capaz de resgatar a realidade psíquica da criança é orientada pela hipótese de que as manifestações da criança são atos de escrita do texto que cifra a leitura de sua relação com a alteridade".

A especificidade da psicanálise de crianças se refere à posição do sujeito em relação ao significante, que não é a mesma do adulto. Trata-se de um tempo lógico em que os efeitos produzidos pelo significante no campo subjetivo dependem do enodamento entre os registros RSI ao qual a significação está submetida (Jerusalinsky, 1990). Isto é o que constatamos com a poética expressão: "ela se conjuga no futuro anterior" (p.13). Estaria Jerusalinsky se referindo à antecipação a que toda criança se vê submetida, por já estar, desde muito antes de nascer, inserida em uma ordem simbólica que pré-existe a ela; entretanto, será pela via de uma colagem identificatória que ela irá semblantear a realização de um ideal parental; e é por isso que o menino brinca de carrinho - "agora eu era o papai", e ela brinca de casinha, brinca de bonecas, enquanto o "papai" estrategicamente sai para "trabalhar" - "Agora eu era a mamãe". Assim eles ensaiam e sonham um futuro já há muito tramado, tecido, imaginarizado e, portanto, subjetivamente, o seu relógio está adiantado.
A direção do tratamento de uma criança deve levar em conta a "posição temporal do inconsciente ${ }^{5}$, onde $\mathrm{o}$ infantil se caracteriza, precisamente, pelo adiantamento do relógio brando da infância" (Jerusalinsky, 1990, p.14).

Entretanto, o infans, sujeitinho suposto, embora imerso no universo simbólico, ainda não acedeu à linguagem, e, portanto, ainda não pode conjugar-se; esse é o tempo da aposta do outro que, antecipando-o enquanto sujeito, cuidando e desejando coisas por ele, vai imprimindo em seu psiquismo as marcas que se inscreverão na memória como letra, "como traços que, a posteriori, serão tomados numa posição particular por uma injunção significante". É bem verdade, diz Jerusalinsky (1991, p.21), "que, a certa altura da exposição de um pequeno bebê à obra do Outro, em razão de sua intromissão significante e de seu trabalho arbitrário de significação esse aparece capturado por esse agir do significante sobre os traços que formam restos mnêmicos... que são tomados associativamente, numa certa posição de significação edípica".

Pois bem, os psicanalistas aprenderam com Freud que há um saber inconsciente que circula entre a mãe e o seu bebê, saber este que o desejo se incumbe de colocar em movimento. Desde o ponto de vista lógico, a mãe é engendrada pelo bebê, uma vez que esta só se torna mãe a partir de um filho e, desde a lógica do inconsciente, a partir do lugar que ela, en- 
quanto filha, ocupou no desejo de seus pais. A maternidade sofre as vicissitudes de um tempo lógico em que, para conjugar-se e apropriar-se do "agora eu sou uma mãe", não basta ter um filho, é preciso que antes tenha havido uma inscrição marcada pelo desejo do outro. Ocorre-me a sofrida constatação de uma jovem mãe com o seu filho de três meses nos braços: “eu não me sinto mãe, eu não sei o que fazer com ele, parece que dependo de autorização para ser mãe".

A maternidade é um momento oportuno para reativar os traços mnêmicos inconscientes da maternagem recebida e possibilitar o exercício de sua função (Cabussu, 2003). Uma mãe bem posicionada na estrutura simbólica irá supor que o seu filho é um sujeitinho bem sabido, capaz inclusive de ensinar-lhe coisas, daí a razão para as mães conversarem com o seu bebê e considerarem o que ele tem a dizer, mesmo que para isso tenham que falar em seu nome. E as mamães logo descobrem a paixão desse bebê por uma fala meio insólita, embalada por uma $\mathrm{voz}^{6}$ encantada e exagerada, signo de um gozo inconfundível. Parece que mãe e filho desconfiam que haja um importante desafio a se fazer cumprir: inserir e ser inserido no universo da linguagem. O trabalho arbitrário de codificação que o outro se incumbe de realizar se observa na escuta de pais, mais precisamente a mãe, que fala manhês com o seu bebê - ávido de linguagem e aparatado para se comunicar ${ }^{7}$ - e, cuja palavra, raramente oferecida numa posição a dar lugar a um sentido unívoco. A complexidade desta interlocução deriva do fato de a mãe antecipar e atribuir ao seu bebê uma posição subjetiva tal, como se este, de fato, pudesse sustentá-la. Essa loucura necessária às mães, como dizia Winnicott (1979), suporta um excesso de sentido que sustenta precocemente o pequeno sujeito, e o introduz no universo simbólico, salvando-o de uma identificação ao próprio corpo. Esse excesso de sentido bem que poderia ser traduzido pelo sem-sentido do manhês e da lalíngua, como postula Ferreira (2010, p.67): "Se podemos falar do sem-sentido do manhês, tanto quanto do semsentido da lalíngua, é somente na proporção em que, não sendo possível vislumbrar um significado em grande parte das alocuções maternas, seja um sentido acessível (consciente) à mãe, à criança (pela sua condição de infans) ou ao observador, é justamente porque há gozo".

Enquanto ser de linguagem, o ser humano se inscreve como sujeito desejante a partir do Outro que dará sentido ao seu apelo, identificando-o como demanda. Esta é a saída e, paradoxalmente, 
também a armadilha com a qual o pequeno terá que haver-se, onde poderemos situar um indicador clínico de risco, e que poderá ser a razão do sofrimento do bebê: o sentido vem do Outro e em conformidade com seu desejo e sua lei, e o sentido pode faltar. Isto ocorrendo, se o saber do Outro vacila, obstáculos se interpõem no devir do sujeito e a promessa tácita entre mãe e filho pode não se cumprir, seja pelas dificuldades intrínsecas à história desta mãe, seja por uma dificuldade do bebê cujo aparato orgânico não esteja em condições de interagir (Kupfer, 2000) e se deixar marcar pelo desejo do outro, ou pela sensibilidade daquele bebê que não se deixa enganar pelo que o carinho materno visa ocultar; diante dessas circunstâncias, podemos nos defrontar com uma mãe impotente, destituída e desautorizada e um bebê em sofrimento psíquico, que apela pelo viés de um sintoma no corpo, do qual ele não poderá fazer cargo. A partir daí, os pais nos procuram supondo um saber que, em princípio, estaria do lado deles.

Após ouvir da mãe de um lindo bebê de cinco meses que apresentava transtornos do sono: "eu quase não trazia ele, pensando que não precisava”. Ocorreu à analista dirigir-se ao bebê e dizer: - "que espertinho, você, tão pequenininho e já trazendo papai e mamãe para conversar comigo!". Esta é uma particularidade da clínica de bebês, na transferência com os pais, as intervenções analíticas vi- 
sam o laço pais-bebê, e para que esta se alavanque e se possam extrair as consequências disto, o bebê deve ser incluído na série e antecipado como um sujeito suposto saber do que lhe causa. Daí o analista também ocupar, na transferência, o lugar do bebê, ora falando por ele, "semblanteando" o transitivismo materno ${ }^{8}$, ora dirigindose a ele, fazendo deste um interlocutor - agora desde um lugar terceiro. Será por esse viés que as intervenções poderão alcançar sua eficácia junto aos pais e promover uma mudança na posição subjetiva destes; subjetividade que se refletirá na interação paisbebê $\hat{}^{9}$. Tal intervenção, se por um lado visa o bebê, reconhecendo no seu sofrimento uma forma de dizer que algo não vai bem entre eles, por outro, visa o Outro do bebê, abrindo uma brecha que possibilite a modalização da demanda de atendimento - é verdade, diz a mãe, com um meio-sorriso, "acho que somos nós que estamos precisando". Observamos que assim os pais têm uma boa oportunidade para começarem a falar de sua história. Escutar os pais, o que eles demandam; situar o lugar do filho no seu narcisismo e no seu discurso, como o fazia Dolto (1984), bem como a representação desse filho no imaginário materno, possibilitará uma leitura que desvele a função do filho e do sintoma no filho. A escuta da demanda visa sua elaboração e modalização, possibilitando uma implicação dos pais nas produções sintomáticas do filho. Logo nas pri- 
meiras entrevistas o bebê já havia recuperado o sono perdido, no entanto, a mãe concordou em ser encaminhada a outro analista.

Comungamos com a opinião de Jerusalinsky (2002) quando a analista se refere à necessidade de se diferenciar o "mal estar dos pais" daquilo que constituiria um impasse à estruturação subjetiva do bebê. Atender um bebê em tais circunstâncias seria condená-lo a encarnar o sintoma em seu corpo, e obstruir a fala parental que, caso fosse escutada, poderia, pelo seu desdobramento, deslocar o foco de queixa do bebê. Saber olhar o bebê, segundo Coriat (1997) implica o reconhecimento das marcas do Outro no seu corpo, ler esta escrita e intervir considerando os protagonistas dessas marcas. Marcas que Laznik (1999) propõe sejam lidas através dos sinais pulsionais do bebê.

Contudo, prossegue Jerusalinsky (2002), uma vez observado um sintoma clínico, este deve ser lido considerando o circuito demanda-desejo no qual o bebê está implicado, ou seja, devemos observar como a imagem de seu corpo ${ }^{10}$ está se constituindo e as inscrições simbólicas que a fantasia materna vai imprimindo nele.

A clínica psicanalítica de bebês, na medida em que estes não "falam", comporta uma singularidade - não se pode escutá-los do mesmo modo como se escuta uma criança que já encena em seu brincar a apropriação dos significantes do Outro ${ }^{11}$. Trata-se, pois, de escutar o Outro do bebê e o bebê do Outro, para que possam ser lidas as letras desse Outro cunhadas no seu corpo ${ }^{12}$.

Jerusalinsky (1988) estabelece uma correlação entre o brincar ${ }^{13}$ da criança enquanto suporte de um dizer e o sintoma psicossomático do bebê enquanto suporte de um traço significante do Outro; segundo o autor, "Uma criança suporta em seu brincar o dizer do que ainda não pode falar. Assim como o bebê suporta, na psicossomática e em uma implicação corporal, o traço significante que o captura no dizer do Outro para além de sua insuficiência verbal" (p. 49).

Um breve exemplo de indicação de atendimento ao bebê e seus pais no qual pudemos constatar os efeitos decorrentes de um processo de constituição subjetiva em risco e que se refletiam no desenvolvimento, na dificuldade de aquisição da fala de um menino de dois anos de idade. Manuelito é trazido pela mãe que, ao marcar a consulta por telefone, relata o diagnóstico de autismo dado pela psiquiatra devido às "dificuldades de linguagem" (ele praticamente não verbalizava, sua tentativa de comunicação resultava enigmática, emitia estranhos e incompreensíveis sons guturais, gritava muito e 
jogava os objetos da casa pela janela).

Inicialmente eles são recebidos sem a presença do pai que não pode vir devido ao trabalho. Manuelito tem um olhar incrivelmente brilhante, perscrutador, e me devolve um sorrisinho matreiro e cativante, um elemento a mais que encoraja e leva a analista a ignorar o diagnóstico inicial e apostar num prognóstico mais favorável. Segundo a mãe, o pai é muito calado, e acha que seu filho se parece com ele, não tem problemas e que é normal, nessa idade, uma criança fazer birras e ainda não falar muito, no que, em parte, ele tem razão. Tomo essa posição do pai como algo positivo, já que reserva ao filho um lugar na filiação e uma possibilidade outra que a repetição de uma história, porém, há nuances importantes que ultrapassam o fato de ele ainda não falar, como veremos em seguida.

Recebo mãe e filho durante vários encontros em que esta fala de um episódio de depressão durante a gravidez e consequente hospitalização após a morte da mãe; relata sua história de sofrimento e abandono diante das dificuldades que enfrenta com os dois filhos (o primeiro, de oito anos, também diagnosticado autista). No imaginário da mãe, a história parece repetir-se, é mister que se empreenda com ela a separação simbólica entre os dois filhos, cujo desejo, necessidades, dificuldades e possibilidades são diferentes. $\mathrm{O}$ trabalho analítico começará por essa linha, até que a mãe con- ceba a possibilidade de um destino diferente para cada um e possa ofertar a esse filho outra representação com a qual ele possa vir a se identificar.

A representação de um filho no imaginário materno cultivada durante a gestação é um assunto que ocupa o interesse da analista há algum tempo Barbosa (2007). Nesse caso, não constatamos uma ausência de representação, o que certamente seria mais grave, mas uma representação, provavelmente potencializada pelo estado depressivo da mãe, e que o diagnóstico psiquiátrico veio confirmar: "vou ter mais um filho com problemas, vou prosseguir com a minha viasacra de médico em médico". É importante ressaltar que esta mãe cuida bem de seus filhos, estão sempre limpinhos e bem alimentados. O que defendemos, e esta mãe vem ilustrar às avessas, é que uma representação que uma mãe tenha do seu bebê concorre para o investimento narcísico e o bom andamento do exercício de sua função, a qual ultrapassa os cuidados e preocupações maternos.

Durante as entrevistas, Manuelito entra tranquilo e sorridente indo direto aos brinquedos. Espalha-os, porém estes não são utilizados na extensão de suas possibilidades simbólicas, são manipulados e arremessados com violência em várias direções, enquanto grita, ininterruptamente, com todas as suas forças; a mãe não o socorre e parece estar diante de uma cena rotineira e trivial; esta cena lhe reporta sua dificuldade de brincar 
com o filho, já que ela "não brincou quando criança", e a dificuldade de saber o que ele quer, já que ele verbaliza muito pouco e de forma bastante truncada; diante desses obstáculos, ela não se autoriza a aventurar-se pelo viés do seu desejo, não codifica seus gestos e não lhe ocorre perguntar ao filho o que ele quer, embora saiba que ele quer alguma coisa. É interessante notar que, embora haja uma suposição de sujeito, não há uma suposição de saber nele, provavelmente devido à representação que ela tem dele - um outro filho autista - como também pelo fato de se sentir fracassada enquanto mãe, de não supor em si um saber sobre o filho. A atitude materna frente à demanda do filho, a falha da função observada na dificuldade de lançar mão de seu repertório particular para significar a demanda do filho e de fazer dele seu interlocutor (Barbosa, 2009), a angústia e a falta de recursos para elaborá-la, evidenciados na pobreza simbólica do seu brincar, denunciam um sintoma clínico; é preciso intervir, emprestar-se como o Outro do bebê.

Certa vez Manuelito foi atendido na sala de espera: ao chegar a sua vez, observo certa lentidão nos seus passinhos, algo que contrastava com as vezes em que ele adentrava correndo, assim que a porta se abria - "o que esse passinho quer dizer, Manuelito?" Ele sorri e busca os brinquedos da sala de espera. O efeito desta leitura pode ser observado algumas sessões seguintes: Manuelito começou a arrastar seu pézinho quando anunciei o final da sessão: "veja doutora", diz a mãe: "ele não quer ir embora, agora você quer ficar, é? É, danadinho?" - ele abraça a mãe e diz - "é". Acolher a demanda de Manuelito, dilatando o tempo da sessão, foi também uma maneira de endossar a interpretação materna e legitimar-lhe o lugar de Outro do bebê.

Um pequeno recorte clínico de sessões ocorridas após um ano de atendimento: Manuelito "batuca" com suas mãozinhas no divã extraindo um som que o surpreende e convoca o olhar da analista, o que o leva a repetir sua façanha. $\mathrm{O}$ ritmo de sua batida evoca uma conhecida música espanhola e a analista começa a cantarolar; o curioso é que a analista não sabe a letra, mas a música, esse novo sentido, o empolga, ele dança, grita e o grito, antes estranho, agora parece familiar, já que, mesmo sem palavras, passamos a compartilhar o mesmo código, elemento essencial para o gancho transferencial. A partir de então, as sessões começarão com o grande concerto do pequeno percussionista que, por um bom período, não dispensará o olhar e a voz da cantora improvisada, objetos $a$ da analista que se deixa fisgar, e que se ofertam como legitimadores de uma produção significante, na qual ele poderá se fazer representar "agora eu era o a(r)tista". Em seguida, Manuelito se interessará por uma parte do corpo da analista: com uma panelinha pega pelo cabo como se fosse a extensão de sua mão, 
Manuelito a faz deslizar pelo rosto da analista que lhe diz: humm ...que mãozinha gostosa e carinhosa você tem! Algumas sessões mais tarde, ele envolverá o rosto da analista com suas próprias mãozinhas e por um longo tempo empreenderá essa pesquisa que lhe parece fascinante e lhe devolve um semblante de satisfação quando percebe que a analista-espelho vai nomeando as expressões de seu rosto.

À medida que ele vai reconstituindo sua imagem, ele vai podendo retornar, desde outra posição, aos pequenos objetos $a$ próprios da infância e suportes materiais que lhe possibilitam a expressão da fantasia; os talheres e as panelinhas cobram seu status de utensílios e ele fará deliciosas comidinhas, alimentará a analista, alimentará a mãe e se deixará alimentar por ela. Se nos conduzimos pelos ensinamentos de Lacan (1998, p. 822) quando ele diz que "a fala só começa com a passagem do fingimento à ordem do significante", podemos pensar que Manuelito está trilhando o caminho certo, contudo, ainda incerto, de sua constituição subjetiva. Embora ainda apresente dificuldades na fala, ele entende os enunciados e já constrói pequenas frases como "me dá água”, ao invés de "agu”, “ quero não", ou "quero", ao invés da simples menção com a cabeça; o nome da analista foi incluído na série e a mãe relata que vir para o consultório é uma atividade prazerosa para ele; os gritos na sessão foram substituídos pelo que hoje parece ser sua expressão prefe- 
rida, o "não", às vezes seguido de um sorriso zombeteiro, o que denota uma mudança de posição do sujeito na linguagem, instituída pelo corte, pela separação entre o sujeito e o outro.

O manejo da transferência com a criança pequena, mesmo que ainda não verbalize muito, requer do analista uma estratégia que a inclua, de fato, no discurso. Desde o início, sempre que a analista precisou contatar os pais pelo telefone, Manuelito era chamado e lhe era explicado o motivo. Assim, ele ficava sabendo quando a analista poderia atendê-lo ou não, ou quando a analista constatava sua ausência na sessão anterior. Os pais, do outro lado da linha, diziam que ele parecia entender tudo, principalmente quando ele esboçava seu risinho maroto, muito embora dissessem não entender a razão da atitude da analista; nessa estratégia, o manejo da transferência visa o laço pais-bebê, outorgar a ele um lugar privilegiado de sujeito visa efeitos na sua subjetividade e na dos pais.

A demanda e a transferência revelam, nessa extensão, a especificidade desta clínica em seu aparente paradoxo: o suposto sujeitinho, nos primórdios de sua constituição, está necessariamente alienado ao outro, daí ele ainda não poder arcar com simbolização, das letras impressas nele, ao mesmo tempo em que o constituem; se, por um lado, a intervenção analítica considera a posição temporal do inconsciente na infância, que é diferente da do adulto, em se tratando da clínica de bebês, deve-se considerar a especificidade de um tempo em que o sujeito do inconsciente ainda não se inscreveu - trata-se do tempo da inscrição da letra ${ }^{14}$. Nesse tempo privilegiado das primeiras coordenadas da estruturação psíquica, estamos prestes a testemunhar e intervir num tempo primordial em que as experiências precoces marcam e fundam o psiquismo o que coloca em relevo uma ética que só se sustenta, na transferência, pela confluência de desejos díspares - o desejo inédito do analista, e desejo do outro, posto que sua função é desejar ${ }^{15}$.

A PSYCHOANALYTICAL CLINIC: SPECIFICITY BETWEEN CHILDREN AND BABIES ALSO

\section{Abstract}

In the beginning, important contributions of Melanie Klein and Anna Freud showed us the specificity of the psychoanalytical clinic for children. However, if this subject resulted in a change in the technique for treating children, we propose a more specific approach when dealing 
with babies. Nowadays, after many decades of clinical history, we will see that, besides the importance of a clinic strategy appropriate to the child and baby's psyche, the proposition of Lacan that the unconscious is structured as a language will allow an analytic intervention.

Index terms: newborns; psychoanalytical clinic; children; child psyque.

\section{LA CLÍNICA PSICOANALÍTICA: DESDE LOS NIÑOS A LOS BEBÉS, UNA ESPECIFICIDAD}

\section{RESUMen}

En su origen la clínica psicoanalítica de niños nos brindó con los importantes aportes de Melanie Klein y Anna Freud, las cuales nos señalaron la especificidad de esa clínica. Si lo que antes ocupaba a las psicoanalistas repercutía en la técnica a ser usada con niños, nuestra propuesta sustenta una especificidad todavía más singular cuando se trata de bebés, una vez que no pueden ser escuchados de la misma manera que se escucha a un niño que ya escena en su juego la apropiación de los significantes del Otro. En la actualidad, después de décadas de historia clínica, veremos que, además de la importancia de una estrategia clínica apropiada al psiquismo infantil, será en la relación del inconsciente com el lenguaje que esta clínica encontrará subsidios que autoricen una intervención analitica.

Palabras clave: bebés; clínica psicoanalitica; niños; psiquismo infantil.

\section{REFERÊNCIAS}

Aberastury, A. (1986). A psicanálise da criança. Porto Alegre: Artes Médicas.

Barbosa, D. C. (2007). Da concepção ao nascimento, a razão da intervenção precoce. Estilos Clínica: Revista sobre a Infância com Problemas, 12 (23), 68-77.

Barbosa, D. C. (2009). A função materna, seus entraves e o sintoma do bebê. In E. F. L. Oliveira, S. S. Ferreira \& T. A. Barreto (Orgs.), As interfaces da clinica com bebês (pp. 147-57). Recife: NINAR - Núcleo de Estudos Psicanalíticos.

Cabassu, G. (2003). A clínica precoce, história de uma colaboração psicanalista/ pediatra. In M. Leitgel-Gille (Org.), Boi da cara preta: crianças no hospital (pp.4666). Salvador: EDUFBA: Ágalma.

Catão, I. (2009). O bebê nasce pela boca: voz, sujeito e clínica do autismo. São Paulo: Instituto Langage.

Coriat, E. (1997). Psicanálise e clínica de bebês. Porto Alegre: Ed. Artes e Ofícios.

Cullere-Crespin, G. (2004). A clínica precoce: o nascimento do bumano. São Paulo: Casa do Psicólogo.

Dolto, F. (1984). Psicanálise e pediatria. Rio de Janeiro: Zahar Editores.

Ferreira, S. S. (2010). Será o manhês uma exclusividade da função materna? In D.C. Barbosa \& E. Parlato-Oliveira (Orgs.), Psicanálise e clínica com bebês: sintoma, tratamento e interdisciplina na primeira infância (pp. 51-73). São Paulo: Instituto Langage. 
Freud, S. (1988a). Análise de uma fobia em um menino de 5 anos. In S. Freud, Edição standard brasileira das obras psicológicas completas de Sigmund Freud (J. Salomão, trad., Vol. 10, pp.15-152). Rio de Janeiro: Imago Editora. (Trabalho original publicado em 1909)

Freud, S. (1988b). Novas conferências introdutórias sobre psicanálise. In S. Freud, Edição standard brasileira das obras psicológicas completas de Sigmund Freud (J. Salomão, trad., Vol. 22, pp.167-191). Rio de Janeiro: Imago Editora. (Trabalho original publicado em 1933)

Jerusalinsky, A. N. (1988). Desenvolvimento: lugar e tempo do organismo versus lugar e tempo do sujeito. In A. N. Jerusalinsky, e Cols. Psicanálise e desenvolvimento infantil: um enfoque interdisciplinar. Porto Alegre, RS: Artes Médicas.

Jerusalinsky, A. N. (1990). Seminário: a direção da cura na psicanálise com crianças. In Associação Freudiana da Bahia, Caderno de transcrição e tradução s/n. Salvador. Inédito.

Jerusalinsky, A. N. (1991). Seminário: as identificações na cura psicanalítica. In Associação Freudiana da Bahia. Caderno de transcrição e tradução $\mathrm{s} / \mathrm{n}$. Salvador. Inédito.

Jerusalinsky, J. (2002). Enquanto o futuro não vem. Rio de Janeiro: Ágalma.

Jerusalinsky, A. N. (2010). Psicopatologia dos bebês: entre as neurociências e a psicanálise. In D.C. Barbosa \& E. Parlato-Oliveira (Orgs.). Psicanálise e clínica com bebês: sintoma, tratamento e interdisciplina na primeira infância (pp. 23-32). São Paulo: Ed. Instituto Langage.

Klein, M. (1975). Psicanálise da criança. São Paulo: Editora Mestre Jou.

Kupfer, M. C. M. (2000). Notas sobre o diagnóstico diferencial da psicose e do autismo na infância. Psicologia USP, 11(1). Recuperado em 23 jun. 2005, da SciELO (Scientific Electronic Library Online): http://www.scielo.br 
Lacan, J. (1985). O seminário, livro 17: o avesso da psicanálise, 1969-1970 (A. Roitman, trad.). Rio de Janeiro: Jorge Zahar Editor.

Lacan, J. (1998). Subversão do sujeito e dialética do desejo no inconsciente freudiano. In J. Lacan, Escritos (pp. 807-842). Rio de Janeiro: Jorge Zahar Editor.

Laznik, M.C. (1999). Os efeitos da palavra sobre o olhar dos pais, fundador do corpo da criança. In D. B. Wanderley (Org.), Agora eu era o rei: os entraves da prematuridade (pp. 129-140). Salvador: Ágalma.

Laznik, M.C. (2004). Introdução. In M.C. Laznik, A voz da sereia: o autismo e os impasses na constituição do sujeito (pp. 13-17). Salvador, BA: Ágalma.

Ledoux, M. H. (1991). A introdução à obra de Françoise Dolto. Rio de Janeiro: Jorge Zahar Editor. Vorcaro, A. M. R. (2004). A criança na clínica psicanalítica. Rio de Janeiro: Companhia de Freud. Winnicott, D. W. (1979). A criança e seu mundo. Rio de Janeiro: Zahar.

\section{NOTAS}

1 Análise que permitiu a Freud assentar os fundamentos para a compreensão da linguagem pré-verbal e utilização da interpretação (Aberastury, 1986), cujos efeitos confirmaram a possibilidade de se analisar crianças, bem como também comprovar suas descobertas acerca da sexualidade infantil.

2 Jerusalinsky (2005, p. 49) “também as estruturas da infância são provisórias. Porque dependem das transformações que se produzem nas relações com este Outro primordial encarnado nos pais".

Lembremos o quanto há de freudiano nesse pressuposto, na insistência do psicanalista em defender, desde o início, - embora isso vá tomando contornos diferentes ao longo de sua obra -, a necessidade de dois tempos para que se configure uma psicopatologia, o tempo da inscrição, na infância, e o da fixação do sintoma, quando chega a puberdade, momento de eclosão da sexualidade e do imperativo da escolha do objeto, a qual comporta uma renúncia à mãe, entanto primeiro objeto de amor.

3 Jerusalinsky (1988) já havia anunciado a "permeabilidade biológica ao significante" (p. 44).

4 Esta correlação entre o desenvolvimento e a constituição psíquica é abordada amplamente por Julieta Jerusalinsky (2002).

5 Jerusalinsky (1990) se refere à posição temporal do Nome-do-pai; segundo ele, a problemática da sexuação é, precisamente, a que determina a posição do inconsciente na infância.

6 Considerando a anterioridade da voz em relação ao olhar, Catão (2009) propõe a voz como o primeiro organizador do caos psíquico em que se encontra o infans.

7 "Desde o nascimento, a criança é um ser de fala, receptivo e ativo, à espera de trocas sensório-motoras da linguagem vocal e gestual, e atento ao outro que o embala, lhe sorri e lhe fala" (Dolto, citado por Ledoux, 1991, p. 24).

8 Para nós, trata-se de semblantear, uma vez que, embora o analista fale pelo bebê, é dos enunciados parentais que ele se vale para intervir. Pensamos nas duas vertentes do laço primordial de que nos fala Cullere-Crespin (2004), que aqui referimos ao lugar ocupado pelo analista na transferência. 
9 E aqui nos reportamos a Laznik (2004): segundo ela, o analista com uma contribuição libidinal poderá operar uma mudança no olhar desses pais em relação ao bebê. A nossa hipótese é que esta mudança se refletirá na imagem real com a qual o bebê poderá se identificar.

10 A imagem inconsciente do corpo, conceito privilegiado da Obra de Dolto, aponta para a precocidade da atividade representativa do infans. Por estar marcada pela dimensão simbólica, esta imagem não se reduz ao imaginário, liga-se à história pessoal e à maneira como se estabelece a relação libidinal com o Outro.

11 Para Coriat "o brincar é o cenário no qual a criança se apropria dos significantes que a marcaram" (1997, p. 303)

12 Propomos uma intervenção quando um bebê apresenta transtornos psicossomáticos, de desenvolvimento ou em situação de risco psíquico (Barbosa, 2007, p.73).

13 Aqui podemos pensar no brincar enquanto sintoma clínico ou de estrutura.

14 Esse tema foi amplamente discutido por Jerusalinsky (2002)

15 Lacan (1985) se refere ao papel da mãe como sendo o desejo da mãe. Ferreira (2010) formaliza e articula o desejo da mãe à função materna.

denise.cb@uol.com.br

Rua Marechal Deodoro, 139/102 48005-020 - Alagoinhas - BA - Brasil.

Recebido em dezembro/ 2010. Aceito em maio/2011. 